\title{
Exploring Students' Use of the Social Networking Site WhatsApp to foster connectedness in the online learning experience
}

\author{
Suzanne Stone ${ }^{*_{1}}$ Anna Logan a \\ a. Dublin City University
}

(Received November 2017; final version received April 2018)

\begin{abstract}
In recent years, increasing attention has been paid to the use of social networking tools in higher education teaching and learning. Drawing on data from a larger study focusing on student engagement in the online virtual classroom, this paper is based on research conducted with three separate cohorts of students from the Masters in Special Educational Needs (MSEN) at St. Patrick's College now the Institute of Education, Dublin City University (DCU). Emerging from the first two phases of the research was the use of the WhatsApp social media tool by students as an informal learning space and a means of building connectedness. We explored this finding in more detail in phases three and four by inviting respondents to comment specifically on their use of social media throughout the programme. It emerged that the use of WhatsApp was widespread, offering students an opportunity to forge a sense of connection and the basis for developing a learning community. This paper will present findings around the use of WhatsApp with reference to literature in three areas connected to the online learning experience: online learning as a second class learning experience, fostering connectedness within online learning contexts and social media and learning.
\end{abstract}

\section{Introduction}

Despite the proliferation of social media and increased interest in social networking in higher education (Purvis, Rodger \& Beckingham, 2016), surprisingly little attention has been paid to exploring the nature of such social practice (O' Keeffe, 2016). At the same time, there is evidence of uncertainty among both academics (Purvis et al., 2016) and students (Dabbagh $\&$ Kitsantas, 2012) regarding the use of social media in professional learning contexts.

\footnotetext{
Corresponding author. Email: suzanne.stone@dcu.ie

Irish Journal of Technology Enhanced Learning Ireland, 2018. (c) 2018 S Stone \& A Logan.

The Irish Journal of Technology Enhanced Learning Ireland is the journal of the Irish Learning Technology Association, an Irish-based professional and scholarly society and membership organisation. (CRO\# 520231) http://www.ilta.ie/ . This is an Open Access article distributed under the terms of the Creative Commons Attribution 4.0 International License (http://creativecommons.org/licenses/by/4.0), allowing third parties to copy and redistribute the material in any medium or format and to remix, transform, and build upon the material for any purpose, even commercially, provided the original work is properly cited and states its license.
} 
Furthermore, it has been argued that the nature and impact of student use of social networks for knowledge sharing and learning has been under-researched ( Eid \& Al-Jabri, 2016). Arguably, social networking can support the creation of communities of practice (Lave \& Wenger, 1991) particularly among online learners, having potential to support learners in integrating formal and informal learning and facilitate self-regulated learning (Dabbagh and Kitsantas, 2012). The salience of social networking initially emerged as an unanticipated finding of research conducted by the authors to explore ways to support student engagement in the formal online synchronous classroom, leading the authors to a closer examination of this theme.

During the academic years 2014-2017, we researched student engagement in the online virtual classroom with three successive cohorts of students from the Masters in Special Educational Needs (MSEN), a blended programme at the former St. Patrick's College, Drumcondra now part of the new Institute of Education, Dublin City University. Initial findings from cohort one suggested that while most participants expressed a preference for the face-to-face classroom, the convenience of the online approach was highly significant in enabling them to complete the programme. Data from the second cohort shed further light on student perceptions and expectations of online learning prior to registration. Emerging from this phase was the use of the WhatsApp social media tool by students as an informal learning space and a means of building connectedness for students who were distance learners for the majority of the programme. We explored this further in phases three and four by inviting respondents to comment specifically on their use of social media throughout the programme. It emerged that the use of WhatsApp was widespread and was seen as a very positive experience.

We begin with a review of the literature in the areas of: online learning as a second class learning experience, fostering connection for online cohorts and social media and learning, with particular reference to the use of WhatsApp. We follow with a short outline of the research context and background and an outline of the research methodology. Drawing on the literature reviewed and considering the connectedness of these themes, we offer an analysis of our findings. We conclude by drawing conclusions and identifying implications for practice and research and suggest how these might inform the development of guidelines for the use of WhatsApp for building connectedness within online student cohorts and building learning communities.

\section{Literature Review}

An initial literature review explored the areas of social media in education and online learning as a second class learning experience. Over the course of the research we returned to explore the further theme of 'connectedness in online learning' with a particular focus on informal learning spaces, which allowed us to frame the research from a broader perspective.

\subsection{Perceptions of online learning as a second class educational experience}

The perception of online learning as a second class educational experience is widely explored in the literature (Bayne, Gallagher \& Lambe, 2014, Raddon, 2006; Ross \& Sheil, 2017). A perceived lack of connection to the campus or 'campus envy' and a longing for the face to face experience is at the centre of this discourse (Bayne et al., 2014). Bayne et al. mention the difficulty with the semantics of online education: students are described as being 
'distant' or 'absent' from the university campus, suggesting that discourse should include discussion about university spaces from a more fluid perspective.

The university, we suggest, can no longer be seen as a bounded, stable place - a static 'container' within which education takes place (p. 3)

Raddon's (2006) study offers an alternative view from a group of distant students over two years of a masters programme who viewed the distance education model as one of opportunity. The participants in this study recognised that attending a full time face to face programme would not have been an option in their own particular context and saw the distant education model as a positive, allowing control over time and location. While some of the participants expressed some 'campus envy' as defined by Ross and Sheil (2017), on balance the distant option was the more advantageous choice. It is interesting to note that within this generally positive perspective of distant learning, participants did view the lack of communication with other learners as one of the challenges, despite the provision of online communication tools. Ross and Sheil (2017) offer an interesting perspective on the perception of the challenges of online learning by students completing a dissertation on an online masters programme. Building on theories of imaginary in social theory (Castoriadis, 1997; Taylor, 2002, 2004), they describe what they call the 'campus imaginary' created.

Ross, Gallagher and Macleod (2013) speak about this perceived deficit as something that needs to be addressed by shifting understandings of 'nearness', which we argue could also be understood as 'connectedness'. They describe nearness as a temporary state involving a variety of elements or stakeholders (people, context and technologies) which is difficult to maintain over a long timeframe for those involved in part-time, distance or blended programmes and suggest that universities need to design strategies to accommodate this shifting sense of nearness.

Interruptions and subsequent returns should therefore be seen as normal in the practice of studying as an online distance learner, and teachers and institutions should work to help students develop resilience in negotiating various states of nearness. Four strategies for increasing this resilience are proposed: recognising nearness as effortful; identifying affinities; valuing perspective shifts; and designing openings (p. 1)

\subsection{Social media tools and back channel communication}

Within the last few years, the concept of a communication 'back channel' has emerged in education in both face to face and online learning contexts (Kearns \& Frey, 2010;

Holland, 2014; Jacobs \& McFarlane, 2005). A back channel is described by Kearns and Frey as 'a network of out-of-class dialogues among students'(p.41). Social media tools are ideally suited to the development of such out-of-class dialogues and in the case of online learners the use of technology may be the only option in terms of building connectedness. It is therefore important to understand how such technologies can support back channel communication. The research in this area also suggests that student engagement with a back channel increases if a sense of connectedness exists (Bouhnik, \& Deshen, 2014).

The literature, however limited, in relation to the use of WhatsApp and other social media tools within education does suggest that these informal learning spaces can be of great benefit 
to students in terms of sharing information, building connectedness and establishing learning communities (O'Keeffe, 2016). Bouknik and Deshen (2014) also note that the simplicity and the option of private message on Whatsapp as a platform contributed to usage by students when compared to that of Facebook. There are of course some negative aspects emerging including the level of distractedness (Purvis et al., 2016) and the sheer volume of communication within such platforms. Bouhnik and Deshen (2014) found that teachers involved in WhatsApp group moderation were at times overwhelmed by the number of interactions, but did find simple ways to deal with this issue - namely to mute conversations at certain times. Another possible challenge to WhatsApp in an education context is that the immediacy of the platform fosters a culture of 'here and now' responses which does not allow students to explore solutions themselves initially (Bouhnik \& Deshen, 2014).

\subsection{The importance of informal learning spaces in fostering connectedness}

The literature identifies barriers to a sense of connection for online learners and the difficulties experienced in fostering such connectedness (Wang \& Gearhart, 2006; Paloff \& Pratt, 2007; Bayne et al., 2014; McDonald, \& Mannheimer Zydney, 2014). Deng and Tavares (2013) compared students views of Facebook and the online learning environment offered by the institution (Moodle) and found that while students were much more active on Facebook, they could not determine whether the level of interaction was due to the user interface or the bonding between the group that emerged outside of the formal learning space.

Bouhnik and Deshen (2014) also identified the possibility of WhatsApp in extending beyond the life of the formal classroom with students in their study choosing to maintain the WhatsApp group beyond graduation which of course can only happen through informal learning spaces owned by the students themselves.

\section{Research Context and Background}

This study and the substantive research focus on student use of social networking is located within the wider context of our research on student engagement and interaction. In the academic year 2014-15 in our roles as learning designer and lecturer, we embarked on a collaborative approach to transitioning the MSEN programme from an entirely face-to-face to a blended model of delivery. This research project subsequently emerged from our concern to support student engagement, participation and learning with a particular focus on the synchronous online classroom. The virtual online classroom tool used for the MSEN programme is Adobe Connect and while we have worked over the last number of years to explore ways to support student engagement in the formal online classroom, there has been a low level of student interaction within the online classes. While the use of a back channel has been found to foster peer interaction and reduce the instructor's burden in the virtual online classroom (Vu \& Fadde, 2013), we remain concerned by the level of discomfort that students are reporting in communicating within the Adobe Connect classroom itself, particularly in relation to speaking on the microphone, and continue to work towards improving this situation.

A very interesting thread emerged from the data around the community building which is happening outside of these formal live online classes. It appears that the formal online learning spaces, the live online classroom and the asynchronous learning activities such as the Loop (Moodle) forum are not perceived by students as conducive to supporting the development of a sense of community within the group. Our findings and analysis to follow, 
explore the efforts of students to counter this perceived deficit in the formal learning spaces by using WhatsApp to create their own interactive space. We reflect on why students have elected to move outside of the formal learning spaces and how we can support this type of connectedness for future cohorts, while allowing students to retain ownership of their informal learning space.

\section{Methodology}

As shown in Table 1, the research was conducted with three separate cohorts of students completing the Masters in Special Educational Needs (MSEN) programme across four phases over the course of three consecutive academic years between 2014 and 2017. The first author was engaged in supporting students to use the Adobe Connect classroom tool through an induction process, answering technical queries from students by email and supporting the lecturer in managing break out sessions. The second author was the programme chair, module coordinator and lecturer throughout all phases of the research. Data were gathered as part of a broader evaluation of the programme in phases 1, 3 and 4 using the Loop (Moodle) questionnaire tool with anonymous respondent settings, and in phase 2 by means of one face-to-face and one online focus group.

Table 1: Data Collection in Each Phase

\begin{tabular}{|c|c|c|c|c|c|}
\hline Phase & $\begin{array}{l}\text { Student } \\
\text { Cohort }\end{array}$ & Year & $\begin{array}{l}\text { Total number of } \\
\text { students in cohort }\end{array}$ & Data Sources & $\begin{array}{l}\text { Number of } \\
\text { participants }\end{array}$ \\
\hline $\begin{array}{l}\text { Phase } \\
1\end{array}$ & Cohort A & $\begin{array}{l}2014- \\
2015\end{array}$ & 29 & Online Survey & 27 \\
\hline $\begin{array}{l}\text { Phase } \\
2\end{array}$ & Cohort A & $\begin{array}{l}2014- \\
2015\end{array}$ & 29 & $\begin{array}{cl}\text { Focus Groups } \\
\bullet \quad \text { Face-to- } \\
\text { face } \\
\bullet \quad \text { Online }\end{array}$ & $\begin{array}{l}5 \\
5\end{array}$ \\
\hline $\begin{array}{l}\text { Phase } \\
3\end{array}$ & Cohort B & $\begin{array}{l}2015- \\
2016\end{array}$ & 23 & Online Survey & 16 \\
\hline $\begin{array}{l}\text { Phase } \\
4\end{array}$ & Cohort C & $\begin{array}{l}2016- \\
2017\end{array}$ & 21 & Online Survey & 11 \\
\hline
\end{tabular}

In Phase 1, at the end of the first semester in December 2014, 27 of the 29 students in Cohort A completed an online survey seeking their views on many aspects of module design, delivery and assessment but with a particular focus on their experience of engagement, participation and learning online. In all, 22 of the 28 survey questions related to online learning and 19 of these were closed questions relating to for example student use of and ratings of the usefulness of tools for engagement such text chat, breakout rooms and the microphone and building relationships online. These data are reported elsewhere (Logan \& Stone, 2016).

In Phase 2, following graduation, all 27 graduates from cohort A were invited to participate in a focus group in order to explore some of the emerging findings in greater depth. Ten 
graduates took part in either a face-to-face or an online focus group interview as was most convenient for them. The focus groups were conducted by a colleague who was not involved in teaching on the MSEN to allow participants speak freely about their experiences on the programme and guideline questions were circulated to participants in advance.

Phases three and four comprised anonymous online questionnaires completed by 16 (cohort B, 2015-16) and 11 (cohort C, 2016-17) students respectively. A key theme emerging from phase 2 was the salience of social media in building community and supporting learning among the cohort. Consequently, some open ended questions relating to students' use of social media applications such as What's App to support their engagement and learning were added to the survey completed by students in cohorts B and C. Respondents were asked to indicate if they were part of a What's App, Facebook group or any other social media group with their peers and were invited to comment on the benefits and challenges of these back channels for their learning. In all phases, information about the study was provided on the online questionnaires and a plain language statement and informed consent forms were included with letters inviting participation in the focus groups. Ethical approval for the study was granted by the Research Ethics Committee of the former St. Patrick's College.

The approach to data analysis was ongoing and iterative throughout each phase of the study (Rosman \& Rallis, 2012; Robson \& MacCartan, 2016). Data from the online surveys were imported into Excel and quantitative survey data were summarised in frequency tables.

The approach to the analysis of qualitative data in responses to open survey questions and to focus group data was inductive, in the style of grounded theory (Glaser \& Strauss, 1967) informed by the systematic approach outlined by Rosman \& Rallis (2012). First, audiorecordings of both focus groups were transcribed in full. Next, having listened to the transcripts, both authors read and reread the transcripts individually, engaging in a process of familiarisation, the identification of categories, data coding and the generation of tentative themes. Then, the authors shared their initial analysis, engaging in a collaborative process of seeking alternative interpretations and explanations leading to the identification of themes for presentation and analysis in light of the existing research literature. The initial themes emerging from the focus group data in phase 2 included themes relating to the broader research relating to the online learning experience in a general sense. Tweleve major themes emerged as shown in Table 2.

\section{Table 2 Overall Themes Emerging from Phase 3 of research - Focus Groups}

1. Perceptions/Prior experience of online learning including perceptions/knowledge of technology required for synchronous online learning

2. Understanding of online learning

3. The positive influence of induction support \& live online support (technical)

4. Induction support - suggestions for improvement

5. Comfort level with technology

6. Distraction element of online learning

7. Teaching strategies - suggestions for improvement

8. Teaching strategies - what worked well

9. Benefits of online learning

10. Preference for face to face

11. Sense of community/lack of

12. Social media as a student support 
Taking the text that was coded as social media support from the Phase 2 focus group (F2F) and the responses from the phase 3 and 4 questionnaires, (in particular WhatsApp) we further analysed this text into three broad themes: The perception of online learning as a second class learning experience; the challenges of fostering connectedness within online learning contexts and using social media tools to build connection for online learners. Within these three broad themes some further sub themes emerged which we feel can be useful in guiding future supports for students: the distraction aspect of back channels; social media and inclusiveness and the need for informal learning spaces.

\section{Findings and Discussion}

In the online questionnaire in phase 1 students in cohort A were asked "To what extent do you feel engaging in online classes helped you to build relationships with your fellow students?" Less than one third of the 26 respondents agreed $(\mathrm{n}=5: 19 \%)$ or strongly agreed $(\mathrm{n}=3: 12 \%)$ while $31 \%(\mathrm{n}=8)$ adjudged engaging in online classes to be not at all helpful, or somewhat helpful $(\mathrm{n}=10: 38 \%)$. Regarding participation in social media groups, 15 of 16 respondents in cohort $\mathrm{B}$ and 10 of 11 respondents in Cohort $\mathrm{C}$ indicated that they were part of a WhatsApp group.

\subsection{Online learning as a second class learning experience.}

Respondents from our own data echo the literature explored above with data emerging indicating that students focused a lot on what they felt was 'missing' from the online learning experience compared to the face to face classroom.

I think in the face to face you're sitting beside someone you're kind of familiar with, if there's anything that you're unclear you might often whisper to them and it's easy then if you've kind of lost track of something or you're not grasping something it's kind of just easy to do it, whereas with the online, you're less likely to ask out if you're not sure of something, you know, you might miss more information that way (F2F focus group 2015/16).

....there's kind of an energy in the room as well, like when you're finished work and tired and come down, like even like here today, like I was tired when I came through the door and I was thinking 'oh I have to concentrate now' but then I picked up the energy in the room and I was like, it kind of woke me up a little bit, but if I was at home now, and just sitting there with a cup of tea listening to you on the computer, it wouldn't be the same. (F2F focus group 2015/16).

Picking up on the the discussion of 'deficit' in online learning by Ross, Gallagher and McLeod (2013) we reflected on how the four strategies suggested for navigating online learning are reflected in our data, recognising nearness as effortful, identifying affinities, valuing perspective shifts and designing openings. Students appear to have taken the initiative to foster 'nearness' or 'connectedness' through the use of WhatsApp, and in doing so have adopted two of the strategies identified above, namely 'designing openings' and identifying affinities. 
By offering students a robust induction for the synchronous online classes, we are acknowledging that a level of effort is required to engage successfully with the content, with the teacher and with the group in the online space, reflecting the above strategy of 'recognising nearness as effortful'. The fourth suggested strategy; shifting perspectives, is a more difficult one to address. Our initial research sought to support the transition from the face-face to the online class and acknowledged the cultural aspect of such a transition by using Falloon's (2011) framework which identifies technical, pedagogical and cultural transitions. While it is clear in our data that students accept they could not pursue studies outside of an online learning opportunity, there is somewhat of a despondent tone in this acceptance, a sense of resignation rather than excitement.

Yeah I think it's really set in stone the type of learner I am I really need to be there, but I was very proud of myself I sat at the laptop for $90 \%$ and listened for about $80 \%$ so I was delighted with that. It did get easier as you went along (online focus group, 2015/2016).

One participant even suggested that the experience had an effect on learning outcomes.

In terms of the time commitment and the travelling there, on a cold wet night, you first miss your cup of tea on your table in your sitting room. D'you know, I think that's the real plus of it, but is that at the expense of the learning outcome? (F2F focus group 2015/16)

As the perceived negatives largely relate to a sense of disconnectedness within the literature and our own data, one strategy that could support a shifting of perspective is to develop guidelines for students around building a sense of connectedness within formal and informal spaces.

\subsection{The importance of informal learning spaces for fostering connection}

Lack of connection emerges from the data throughout each phase of the research.

I think that's important the social interaction. If you have a sense of someone and kind of know them, you are more willing to talk... but it's harder to just talk to an arbitrary name, that's just, you know... I used to do that too, and I used to just think 'ok, who's the person?' (F2F focus group 2015/16)

Certainly the participants of this research study were critical of the affordances of the communication tools within the formal learning spaces:

On Moodle there is a forum that you can write in to, so other than that task... now I have to say, I didn't find, especially in the first year, the forum just kind of fell asunder after and it wasn't used to its full capacity I don't think (questionnaire 2016/17).

More tutors/supervisors should be encouraged to post comments/articles to the forms (forums sic) to encourage students to engage with them and then build up a relationship where students feel able to post queries online (questionnaire 2016/17). 
An analysis of the usage of the social online forum tools in Loop did show some evidence to support this data with a limited number of engagements on the Loop forums (Table 3).

Table 3: Number of Posts to Loop Online Fora

\begin{tabular}{|l|l|l|l|l|l|}
\hline $\begin{array}{l}\text { Student } \\
\text { Cohort }\end{array}$ & Year & $\begin{array}{l}\text { Thesis } \\
\text { discussion } \\
\text { forum }\end{array}$ & $\begin{array}{l}\text { Social } \\
\text { Forum }\end{array}$ & $\begin{array}{l}\text { Qualitative } \\
\text { Research Forum }\end{array}$ & $\begin{array}{l}\text { Assignment } \\
\text { Forum }\end{array}$ \\
\hline Cohort A & $\begin{array}{l}2014- \\
2015\end{array}$ & 8 & 28 & 15 & 12 \\
\hline Cohort B & $\begin{array}{l}2015- \\
2016\end{array}$ & 7 & $25^{*}$ & 22 & 4 \\
\hline
\end{tabular}

*23 of these posts comprised introduction posts during the online induction.

In comparison to the tools available and used on Loop (Moodle) WhatsApp was lauded by the participants.

Yes I was part of the what's app (sic) group. I thought it was brilliant. It was a way to talk and support each other through the whole process and ask any 'silly' questions one may not have liked to ask on the forum or supervisors (questionnaire, 2016/17).

It was used by everyone to have queries answered, advice sought, support and encouragement given. It made us feel like part of a familiar group even though we barely see each other. It will be interesting to see if there is a bigger attendance at this years graduation as a result of the sense of involvement and the class bond that it created (questionnaire, 2016/17)

The dichotomy between formal and informal learning spaces appears to have allowed students the space to take ownership of their own community which reflects the situation in a face to face learning environment. Bayne et al. (2016) identify ethical considerations of the cultures of surveillance as influential in online learning and we can see this influence on the teaching and learning practices in this context. While we know and accept as educators that we cannot control informal learning spaces in the face to face context, the surveillance opportunities of the online learning experience may present a less than complete picture of how informal learning spaces operate. Just because we can monitor online activity more easily does not mean that we necessarily should.

\subsection{Social media tools and connection in education}

It is interesting to look at the list of technology tools mentioned in Kearns and Frey's (2008) study with back channels facilitated by a variety of technology tools ranging from the simple phone call to Skype etc. Obviously, technology trends move on at a rapid pace and WhatsApp was the tool of choice for the students in our study. In effect, the technology is not 
at the centre of this discussion and our data indicates that the affordances and design of WhatsApp are not particularly influencing the use of the tool. We do however, see evidence that it is the freedom of the 'back channel' structure that is important. When comparing the formal and informal communication spaces, one participant comments:

I think, you're not, we'll say, explicitly being monitored, but you kind of feel ... a bit exposed if you kind of maybe express some of your worries or something you're unsure of or you don't understand.

Our data echoes the study by Bouhnik and Deshen (2014) with data illustrating that a sense of connectedness was an important factor in the success of the WhatsApp group.

The contact and support was brilliant. There was a safety provided in being openly honest that's not available online through loop. If I wasn't part of the what's app group it would have been a very different experience. What's app is the news/social forum (questionnaire 2015/16).

Its great to know people are in the same boat as it can be a little isolating when you are completing a distance learning course (questionnaire 2016/17).

Our own data was extremely positive around the use of WhatsApp with some participants naming the interaction within these groups as central to their engagement and indeed completion of the course.

I genuinely would not have completed this course without the support from my WhatsApp peers. It was a lifeline through out the year. No question was left unanswered and we all rallied together to support each other a different stages during the year (questionnaire 2016/17).

We also see evidence of moving from connectedness towards the formation of a learning community.

We'd kind of kept our WhatsApp group going from the Masters and we'd always bounce questions back and forth at one another to the whole group.... I think in terms of social cohesion that's a big part separate from your own motivation to engage (focus group F2F 2015/16).

Equally however, the findings confirm the potential for distraction noted by Purvis et al. (2016) and for students to become overwhelmed by the volume of messages (Bouhnik \& Dreshen, 2014)

At times I had to switch it off e.g. it got very busy during online lectures with people asking questions and commenting. It could be a bit distracting if you let it.

It is quite overwhelming to open your WhatsApp to 300+ messages and having to scroll through these to ensure you haven't missed anything important (questionnaire 2016/17).

It is also of concern that participants seemed to have developed an over reliance on WhatsApp for course information as highlighted in this comment. 
I always checked the messages just to be sure I didn't miss out on anything courserelated (questionnaire 2016/17).

While it is important to support the use of any tool (formal or informal) which supports a sense of connectedness, it is also important for students to have some guidance on using such tools and the affordances and boundaries between the formal and informal spaces.

\section{Conclusions}

This was a very small-scale study carried out with three cohorts of postgraduate students completing one masters level programme within one institution and as such the findings cannot be considered generalizable. Nonetheless, the findings offer a rich source of data to lecturers and learning technologists seeking to harness the potential of social networking sites in fostering connectedness within online student cohorts. Consideration of the findings emerging from the focus groups in phase 2 drew our attention to the salience of WhatsApp for student engagement and learning, and survey data gathered in phases 3 and 4 shed further light on the benefits and challenges arising. It is clear that students on this programme have benefited greatly from using WhatsApp to build a sense of connectedness throughout their programme of study. It is also clear that this sense of connectedness is not currently supported successfully in the available formal learning spaces. Analysis of the data suggests that the benefits related not only to the convenience, accessibility and speed of the social media channel versus the online forums on Loop (Moodle), but also to the private nature of the discussion. While encouraging students to use the Loop app might go some way towards addressing convenience and accessibility, aspects such as speed and privacy are less easily addressed. Arguably, the "instantaneous" nature of responses on social media, valued greatly by several respondents, may itself increase the potential for misinformation and confusion. Nevertheless, the data from this study indicates that students prefer to use an informal private space for posing "silly questions" that they may be uncomfortable asking in an online forum. Furthermore, the data indicated the potential for developing a sustainable learning community for the students beyond graduation in an informal learning space which may not be possible within the formal online learning spaces.

Regarding the implications for practice, it is clear that lecturers working with online learners need to be aware of the existence of social media groups and the positive and potentially negative impact they may exert within their student cohorts. The data emerging from this study suggests that there may be merit in lecturers and learning technologists encouraging the formation of social media groups, pointing out the benefits for building connectedness and in turn, a learning community. In encouraging such practice, it may of benefit to provide guidelines to support effective use of these channels. At the very least, staff could take a lead in ensuring that all students have equal access to participate in pre-existing or newly established social media groups. In the MSEN programme for example students entered the programme at different stages and/or from different routes and consequently some were less connected than others. Furthermore, while most students highly valued being part of the social network, the findings of this study indicate that at times WhatsApp could be a distraction, the volume of messages could be overwhelming and at times a source of misinformation, and at worst, lead to feelings of panic or inadequacy. Drawing on these data, our next step is to develop some guidelines for students around using WhatsApp, highlighting the potential for building connectedness with fellow students and the positive experience of previous cohorts. In the next phase of this research we will collaborate with former students as partners in developing such guidelines. 
The data from this small study sheds some light on the affordances and challenges of social networking for supporting connectedness within online learning communities. In an era where as articulated by a survey respondent "What's app is the news/social forum" we suggest that it is helpful for students and staff to be cognisant of potential benefits and pitfalls of such informal learning spaces. Future research should continue to explore the dynamics of social networking as a learning space in the context of online programmes and the connections between this and the formal learning spaces within a VLE. Such research is both important and timely since as noted by some survey respondents, it is within informal spaces that the learning communities forged can be sustained and developed into the future building capacity and extending learning beyond the confines of the programme timeframe itself.

\section{References}

Bayne, S., Gallagher, M. \& Lamb, J. May (2014). Being 'at' university: the social topologies of distance students. Higher Education. 67, 5, p. 569-583 15.

Bayne, S, Evans, P, Ewins, A, Knox, J, Lamb, J, Macleod, H, O'Shea, C, Ross, J, Sheail, P \& Sinclair, C (2016) Manifesto for Teaching Online 2016.

Bouhnik, D., \& Deshen, M. (2014). WhatsApp goes to school: Mobile instant messaging between teachers and students. Journal of Information Technology Education: Research, 13, 217-231. Retrieved from

Dabbagh, N., \& Kitsantas, A. (2012) Personal learning environments, social media, and selfregulated learning: A natural formula for connecting formal and informal learning. Internet and Higher Education 15, 3-8 Accessed 13th September 2017 , doi:10.1016/j.iheduc.2011.06.002

Deng, L. \& Tavares, N. J. (2013) From Moodle to Facebook: Exploring students' motivation and experiences in online communities Accessed online April 2017

Eid, M., \& Al-Jabri, I., (2016). Social networking, knowledge sharing, and student learning: The case of university students, Computers \& Education, 99, 14-27. https://doi.org/10.1016/j.compedu.2016.04.007

Falloon, G. (2011). Exploring the virtual classroom: What students need to know (and teachers should consider, MERLOT Journal of Online Learning and Teaching 7(4), pp. 439451.

Glaser, B., \& Strauss, A. (1967). The discovery of grounded theory. Chicago: Aldine

Holland, B. (2014) The Backchannel: Giving Every Student a Voice in the Blended Mobile Classroom Retrieved from: https://www.edutopia.org/blog/backchannel-student-voice-blendedclassroom-beth-holland 
Jacobs, N., \& McFarlane, A. (2005) Conferences as learning communities: some early lessons in using 'back-channel' technologies at an academic conference - distributed intelligence or divided attention? Journal of Computer Assisted Learning, 21(5), 317-329. DOI: $10.1111 /$ j.1365-2729.2005.00142.x

Kearns, L. R. \& Frey, B.A. (2010) Web 2.0 Technologies and Back Channel Communication in an Online Learning Community, Techtrends 54: 41. https://doi.org/10.1007/s11528-010$\underline{0419-y}$

Lave, J., \& Wenger, E. (1991). Situated learning: legitimate peripheral participation. Cambridge: Cambridge University Press.

Logan, A ., \& Stone, S. (2016). Collaboration between a lecturer and a learning technologist to support student transition to and engagement and learning in the synchronous online classroom: having the best of both worlds. Published in the proceedings of the International Technology, Education and Development Conference, Valencia, Spain. 7-9 March, 2016. doi: 10.21125/inted.2016

McDonald, J.P. \& Mannheimer Zydney, J. (2012), Going online with protocols: New tools for teaching and learning. New York, N.Y.: Teachers College Press

O'Keeffe, M. (2016). Exploring higher education professionals' use of Twitter for learning Irish Journal of Technology Enhanced Learning, 2(1), 1-16.

http://journal.ilta.ie/index.php/telji/article/view/11/20

Palloff, R. M., \& Pratt, K. (2007). Building online learning communities: Effective strategies for the virtual classroom. San Francisco: Wiley \& Sons.

Purvis, A., Rodger, H., \& Beckingham, S. (2016). Engagement or distraction: The use of social media for learning in higher education.Student Engagement and Experience Journal, 5(1), ISSN (online) 2047-9476 DOI 10.7190/seej.v5.i1.104

Raddon, A. 2006. "Absence as Opportunity: Learning Outside the Institutional Space and Time." Journal of Further and Higher Education 30 (2):157-167. doi:10.1080/03098770600617596

Robson, C., \& MacCartan, K. (2016). Real world research (4th ed.). Hoboken: Wiley.

Rossman, G., \& Rallis, S. (2012). Learning in the field: An introduction to qualitative research (3rd ed.). Thousand Oaks: Sage.

Ross, Gallagher, \& Macleod (2013) Making Distance Visible: Assembling Nearness in an Online Distance Learning Programme Accessed online @ http://www.irrodl.org/index.php/irrodl/rt/printerFriendly/1545/2630

Ross. J. \& Sheail, P (2017) The 'campus imaginary': online students' experience of the masters dissertation at a distance Teaching in Higher Education, Volume 22, 2017 - Issue 7 Pages 839-854 Published online: 28 Apr 2017 http://dx.doi.org/10.1080/13562517.2017.1319809 
Wang H. \& , Gearhart, D. (2006). Designing and developing web-based instruction. Upper Saddle River, NJ: Pearson Merrill Prentice Hall.

Vu, P., \& Fadde, P. J. (2013). When to talk, when to chat: Student interactions in live virtual classrooms. Journal of Interactive Online Learning, 12(2), 41-52. 